\title{
Nuclear Pleomorphism Score
}

National Cancer Institute

\section{Source}

National Cancer Institute. Nuclear Pleomorphism Score. NCI Thesaurus. Code C138978.

A score assigned to a biopsy sample based on the appearance of nuclei in a tumor. 